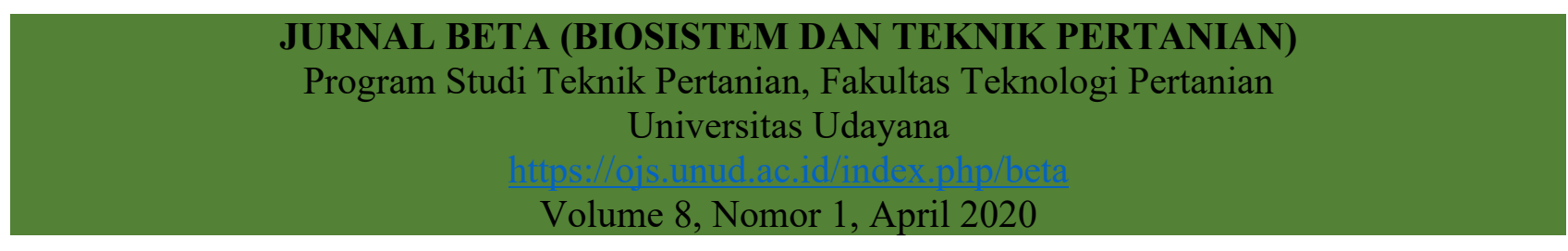

\title{
Switchgrass Bale Automatic Weighing and Watering System
}

\author{
Ni Nyoman Sulastri ${ }^{1 *}$, Shelyn Gehle ${ }^{2}$ \\ ${ }^{1}$ Agricultural Engineering Department, Universitas Udayana, Badung, Bali, Indonesia \\ ${ }^{2}$ Chemical Engineering Department, University of Tulsa, US \\ *email: sulastri@unud.ac.id
}

\begin{abstract}
The purpose of this study was to maintain minimum moisture content for switchgrass bales that were inoculated with Pleurotus ostreatus, a white-rot fungus, in order to start the breakdown of lignin for conversion to ethanol. The moisture content was to be maintained above $50 \%$, which would be monitored using load cells to determine the weight. Three bales were used, and thermocouple wires and hose system were placed at four points inside each bale. In addition, the ambient temperature and relative humidity inside the building were monitored. Bales were inoculated with $1 \%, 2 \%$, and $3 \%$ grain spawn by mass. The inoculation was carried out by taking the bale apart in four places and sprinkling or spreading the fungal spawn over the bale. In order to continuously record the voltage readings from the strain gauges, NI USB6225 data logger and National Instruments' LabVIEW program was used to record and control the system. The develop automatic weighing and watering system had been able to maintain the bale moisture within the acceptable range and the fungus were observed growing. Some issues related to voltage readings and uniformity of water distribution must be addressed for future work.
\end{abstract}

Key words: Switchgrass, Automatic watering system, Automatic weighing system, Fungus pretreatment, Pleurotus ostreatus.

\section{INTRODUCTION}

Switchgrass (Panicum virgatum L.) is a warm season grass and native to North America that has been studied for its potential as a good lignocellulosic biomass for ethanol production (Koff \& Tyler, 2012). The interests on this particular grass are based on its ability to produce a high yield with minimum agricultural inputs and marginal land condition (Scagline-Mellor, Griggs, Skousen, Wolfrum, \& Holásková, 2018). In addition, switchgrass has been widely used for soil conservation in reducing erosion and as a buffer strip to filter excess nutrients from entering water source (Koff \& Tyler, 2012).

Cellulosic ethanol study has been increasingly attractive since the climate change is becoming a major concern in many countries. In order to convert cellulosic biomass to ethanol, the conversion process should be economically feasible and meet quantity and quality goals (Inman, Nagle, Jacobson, Searcy, $\&$ Ray, 2010). Delignification can be done by fungal pretreatment. This pretreatment is simple, requires low energy and reduces costs as well as the waste. White-rot fungi (Pleurotus ostreatus) is a selective delignifier since the cellulose degrades after 21 days of treatments and has been showed a higher lignin degradation in oil palm compared to Pleurotus chrysosporium (Rasnake, Collins, \& Smith, 2013).
The purpose of this study is to maintain minimum moisture content for small square bales of switchgrass for white-rot fungi pretreatment. The ideal condition for growth of this aerobic fungus is between $50 \%$ and $70 \%$ moisture content. These bales will be inoculated with Pleurotus ostreatus, a whiterot fungus, in order to start the breakdown of lignin for conversion to ethanol.

\section{METHODS}

\section{Experiment Set Up}

The major goal of this project was to do a test run of the full-scale project using only three bales. The moisture content was to be maintained above $50 \%$, which was monitored using load cells to determine the weight. Before the experiment begins, the bales are soaked for about 24 hours to obtain an initial moisture content of approximately 55\%. It was assumed that the moisture was evenly distributed throughout the bale, so the weight would be a good indicator of the moisture content. If the moisture content drops below 50\%, the LabVIEW program that was developed would send a signal to a relay to turn on the pump and solenoid valve to add water automatically (Figure 1).

In addition to the weighing and watering systems, it was suggested that temperature inside the bales be 
monitored. Since hay bales have a tendency to spontaneously combust when they become too wet (due to biologically activity), it was necessary to monitor the temperatures. In order to do so, thermocouples were placed at four points inside each bale. In addition, the ambient temperature and relative humidity inside the building were monitored. This test run also involved different fungal loading, which would be important information to select appropriate loading percentages for the full-scale project. Bales were inoculated with $1 \%, 2 \%$, and $3 \%$ grain spawn by mass.

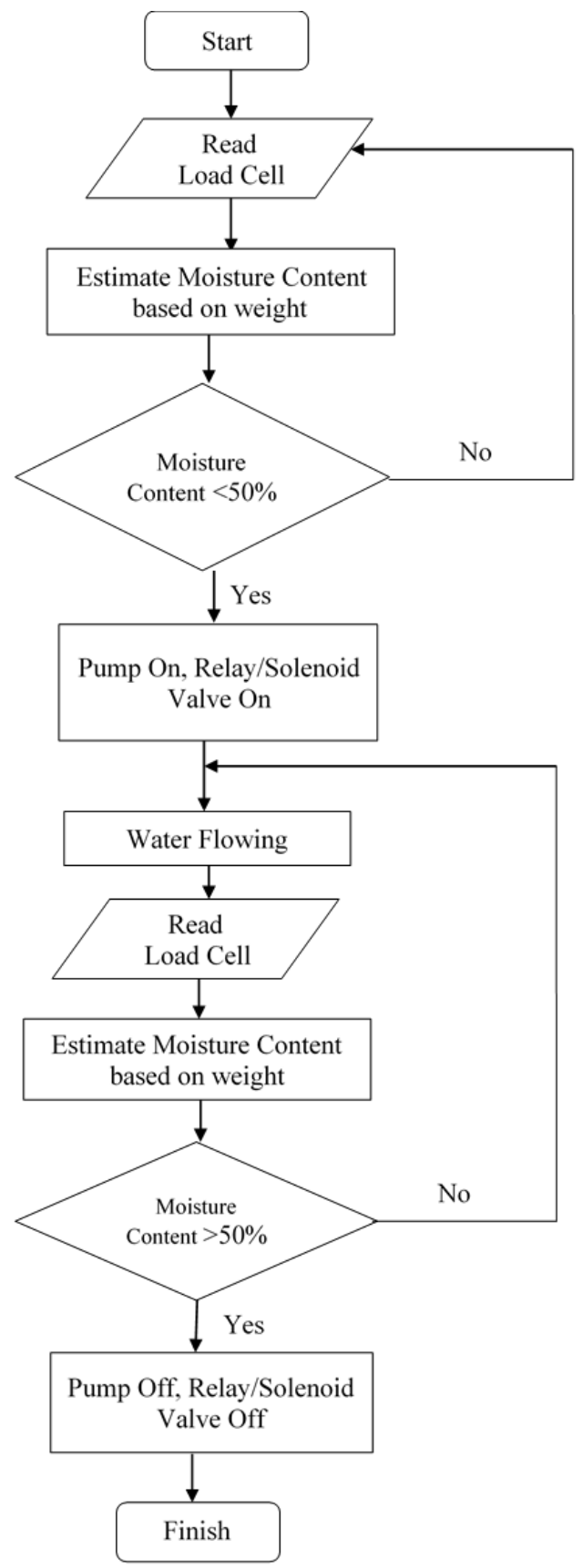

Figure 1. Bale Automatic Weighing and Watering System Flowchart
Table 1 shows the bales weight, fungus added, and strain gauge used. The inoculation was carried out by taking the bale apart in four places and sprinkling or spreading the fungal spawn over the bale. The hose system and thermocouple wires were also added. The bale was put back together, the angle-iron brackets were put on each side and two ratchet straps were used to hold it together. Figure 2 shows the bale rack where all the switchgrass bales were hung on the rack by the load cells using carabiner hooks. The bale rack dimension was (6' x 4' x 8').

Each bale/ strain gauge used two formulas, one for bale weight (equation (1)) and one for moisture content (equation (2)).

$$
\text { Bale }=\frac{V-b}{m}-\text { Straps }- \text { Fungus }
$$

Where, Straps is weight of straps, angle iron frames and hosing, which is equal to $21.036 \mathrm{lb}$, while Fungus is initial weight of fungus added to the bale. The values of $\mathrm{m}$ and $\mathrm{b}$ were taken from calibration curve equation as shown in Figure 3,Figure 4, and Figure 5.

$$
\begin{aligned}
& \text { Moisture Content }(M C) \\
& =\frac{\text { Bale }- \text { Dryw }+(\text { Dryw } \times \text { Mo })}{\text { Bale }}
\end{aligned}
$$

Dryw is weight of the bale before soaking and Mo is initial bale moisture content before soaking (assumed).

Table 1. Bales weight, fungus added, and strain gauge used

\begin{tabular}{cccc} 
Bale & $\begin{array}{c}\text { Strain } \\
\text { Gauge }\end{array}$ & $\begin{array}{c}\text { Dry Weight } \\
\text { (lb) }\end{array}$ & $\begin{array}{c}\text { Fungus } \\
\text { (lb) }\end{array}$ \\
13 & 3 & 41.9 & 0.455 \\
14 & 1 & 39.6 & 0.906 \\
15 & 2 & 39.2 & 1.363 \\
\hline
\end{tabular}



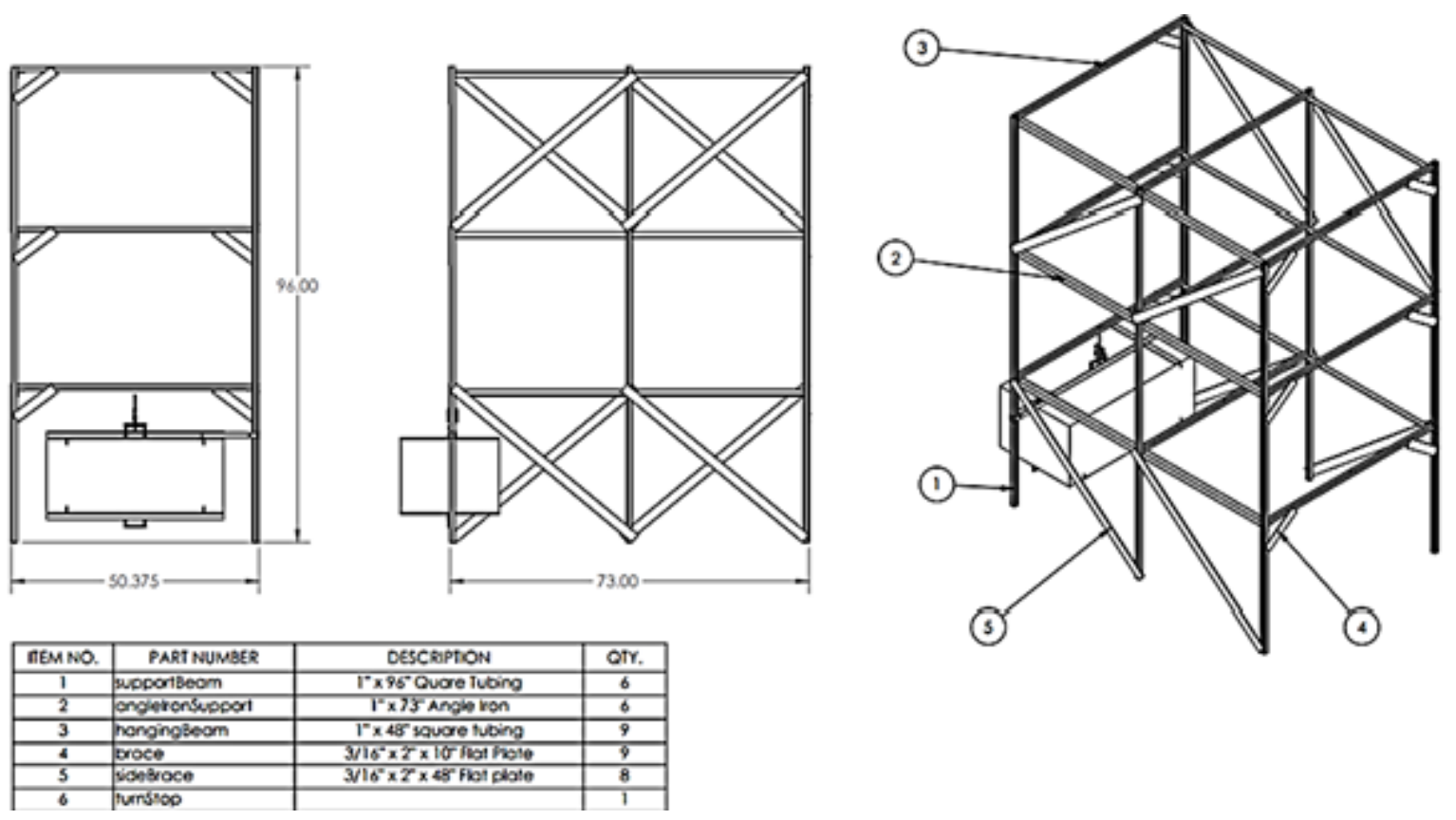

Figure 2. Bale rack SolidWorks drawing

\section{Load Cell Calibration}

Tacuna Systems AmCells STL-200 S-Type Alloy Steel load cells with maximum load of 200 pounds were used. Three strain gauges were calibrated using eight combinations of weight, ranging from 24.7 to $202 \mathrm{lb}$. The voltage was adjusted to compensate for the large metal hook used to hold the weights onto the strain gauge and was calculated by subtracting the voltage reading with the just the hook from the voltage reading with the weight. All the calibration curves showed the linear relationship between voltage and weight with the strength of the regression model, $R^{2}=1$ (Figure 3, Figure 4, and Figure 5).

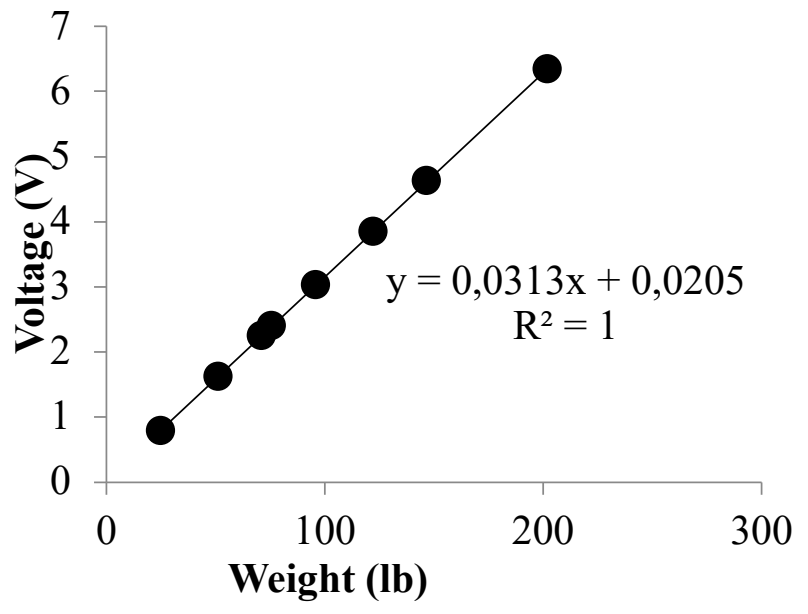

Figure 3. Calibration curve for strain gauge 1

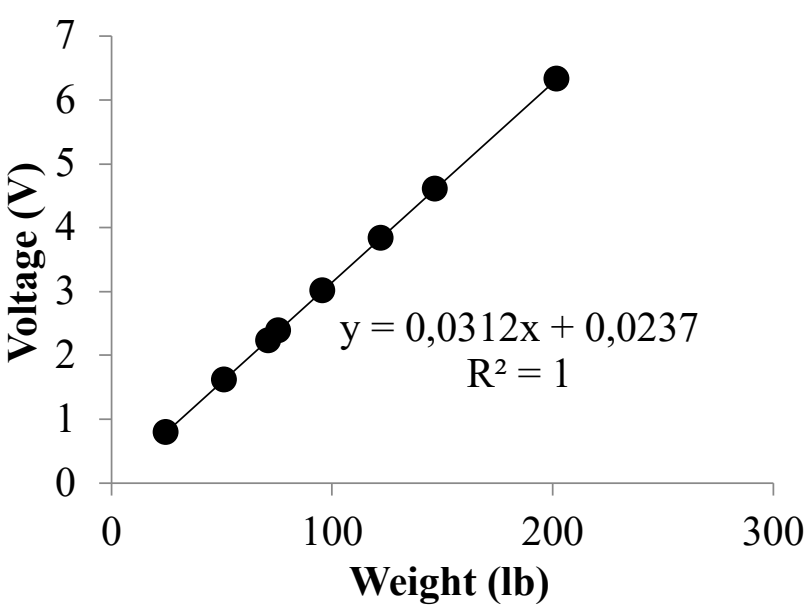

Figure 4. Calibration curve for strain gauge 2

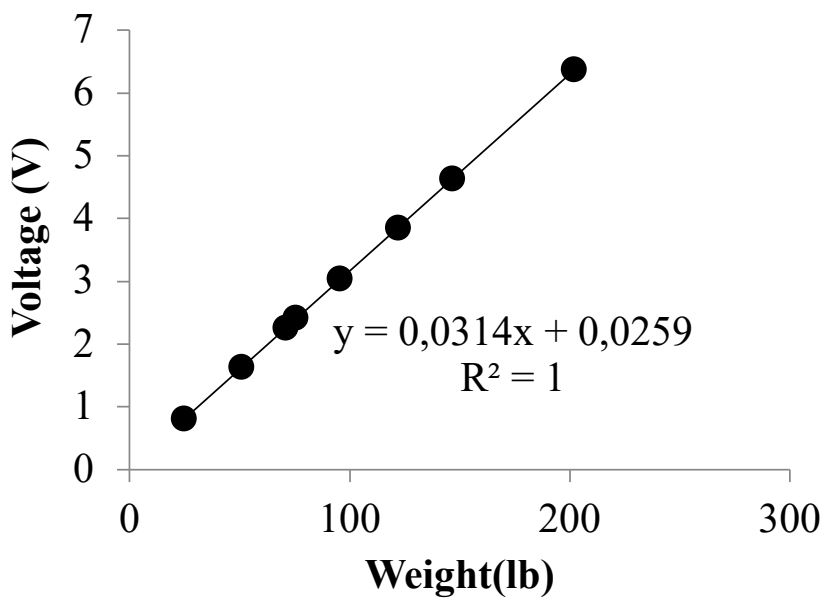

Figure 5. Calibration curve for strain gauge 3 


\section{Load Cell Amplification}

Since the load cells were only capable of outputting a $3.0 \mathrm{mV} / \mathrm{V}$ signal, the differential bridge amplifier LTC1250 was used to amplify the signal. The input voltage was $10 \mathrm{~V}$ with gain resistance of $36 \mathrm{k} \Omega$. Figure 6 displays the load cell amplifier circuit diagram and load cell amplifier circuit board.
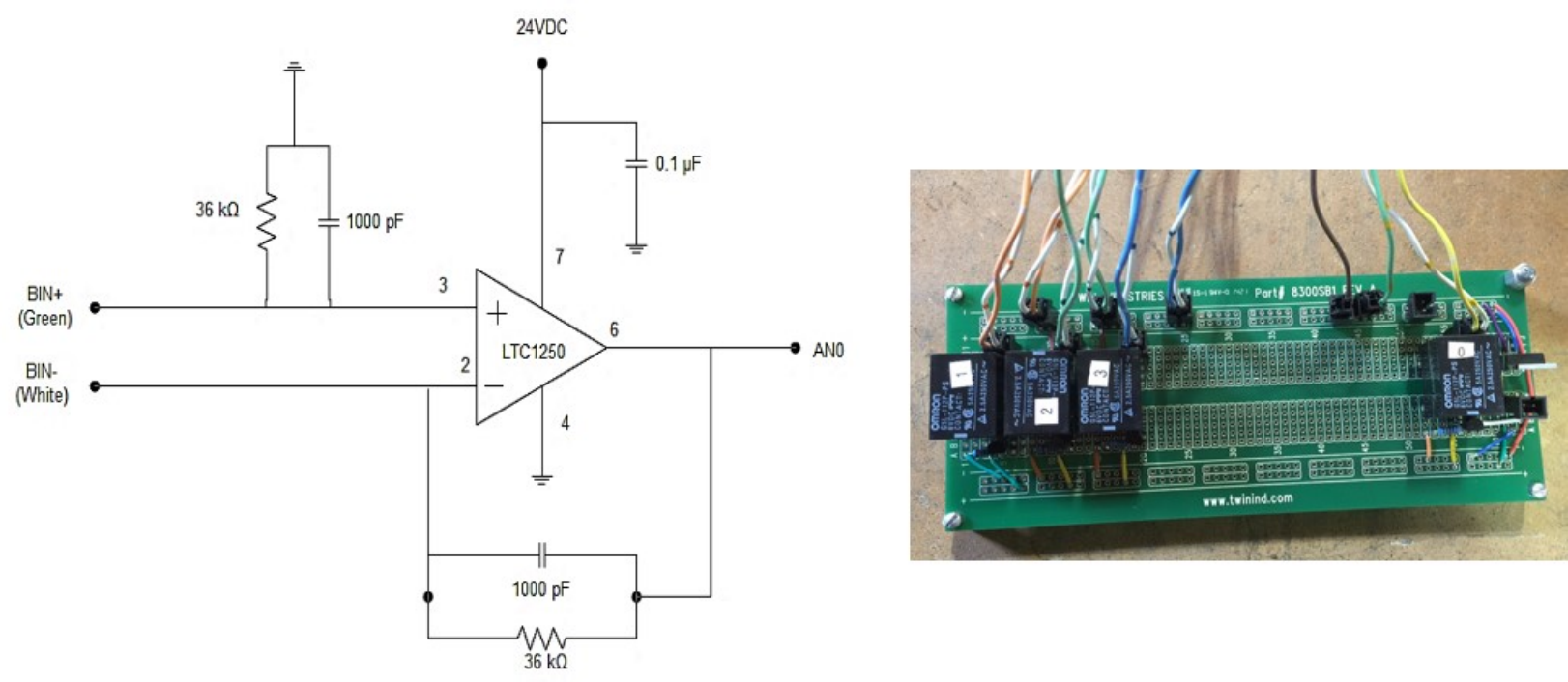

Figure 6. Load cell amplifier circuit diagram and the circuit board

\section{Relays, Solenoids, and Pump}

Relays were used to control power to the solenoid valves and pump. The type of relays, solenoid valves, and pump used were Omron PCB G5L-5V relays, Spartan Scientific Series 3923 Stackable Solenoid valves, and a CountyLine $30 \mathrm{gal} / 2.1 \mathrm{gpm}$ sprayer pump, respectively. The relay to solenoid wiring diagram and the circuit board can be seen in Figure 7. Relays 1,2 and 3 are used to power the solenoid valves and are connected to a $24 \mathrm{~V}$ power supply. Relay 0 is connected to the pump using a $12 \mathrm{~V}, 8.5 \mathrm{~A}$ power supply.
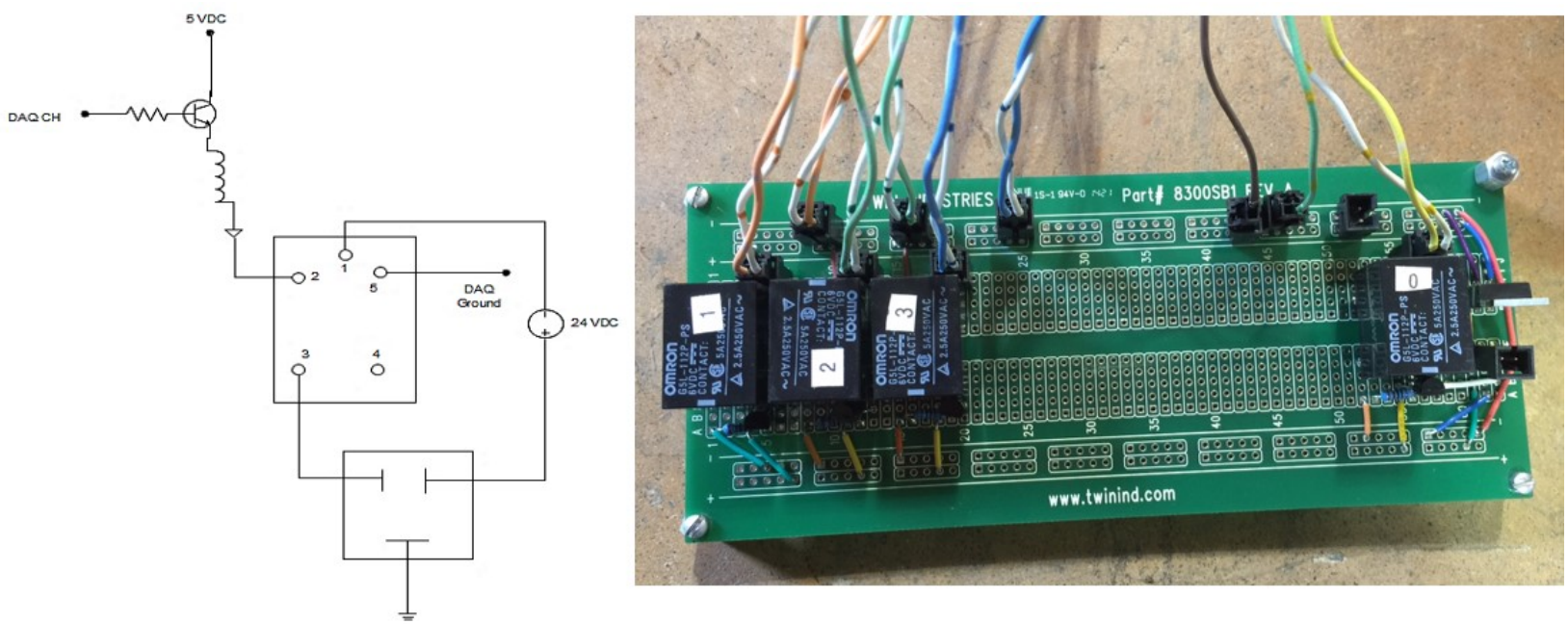

Figure 7. Relay to solenoid circuit diagram and the circuit board

Temperature, Relative Humidity and (Kelvin) was done using the change of resistance Thermocouples value. The equations used to calculate the A HTM2500LF series Temperature and Relative Humidity (RH) module was used to measure ambient temperature and relative humidity. Since it is a thermistor type sensor, the estimation of temperature temperature and $\mathrm{RH}$ were equations (3),(4), and (5).

$$
R=\frac{10000 V}{5000-V}
$$




$$
T\left({ }^{\circ} \mathrm{C}\right)=\frac{1}{a+b \ln R+c(\ln R)^{3}}-273
$$

The value of a is $0.000854942, \mathrm{~b}$ is $0.000257305, \mathrm{c}$ is 1.65368E-7. Those value was from the datasheet provided by the temperature and $\mathrm{RH}$ module company.

$$
R H \%=0.0375(V \times 1000)-37.7
$$

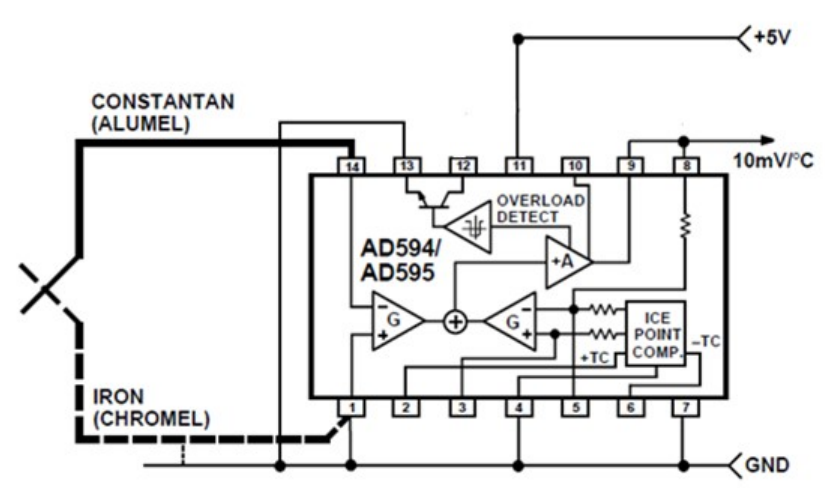

Figure 8. Thermocouple amplifier and the circuit board

\section{Data Acquisition}

In order to continuously record the voltage readings from the strain gauges, a data logger was necessary. NI USB-6225 data logger was used, which has 80 analog inputs and 24 digital outputs. National Instruments' LabVIEW program was used to record and control the system.

\section{RESULTS}

\section{LabView Programming}

There are two components of the VI (virtual instrument) on the LabView: the front panel and the block diagram. The front panel, shown in Figure 9, has several indicators (readings, relays, graphs, etc). The block diagram for this program contains three while loops. The first loop (Figure 10) shows the DAQ Assistant, which reads the voltage signals from the strain gauges, temperature and relative humidity sensor, and thermocouples. The sampling rate was determined by a "ms to wait" control, with 1 sample per minute. Signal manipulation was used to split the signal from the DAQ Assistant, so that individual signals can be analyzed differently. The strain gauge signals were also merged together so they can be

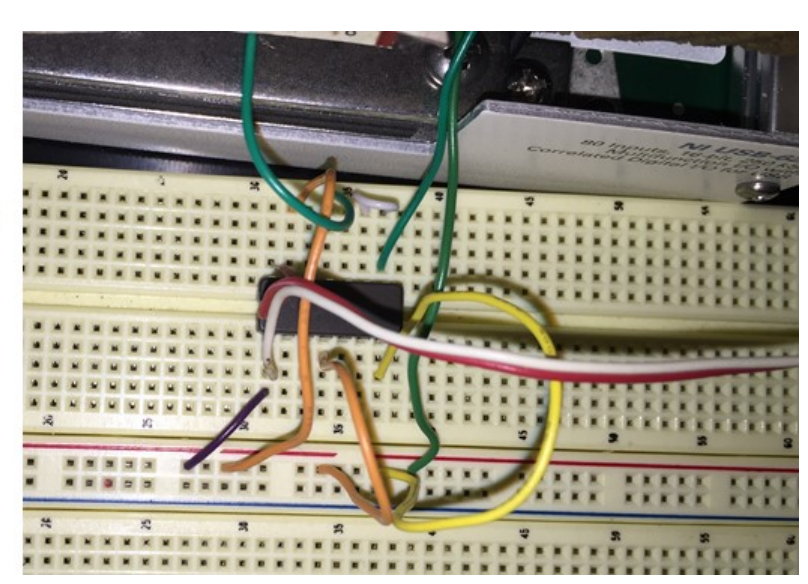

Where, $\mathrm{R}$ is the resistance and $\mathrm{V}$ is voltage reading from the data logger.

J-type thermocouples were used to measure the temperature inside the bales. Each bale has four thermocouple wires. Because of the limitations of analog input of the data logger and the number of thermocouples needed, the differential wiring to provide cold junction compensation cannot be done. Instead, Monolithic Thermocouple Amplifiers with Cold Junction Compensation (AD594) was used to allow the thermocouples to be measured relative to the ground. The output of these thermocouple amplifiers is $10 \mathrm{mV} /{ }^{\circ} \mathrm{C}$. displayed on one waveform chart. Local variables were used to transfer the voltage readings for each channel to the calculations loop.

The second loop (Figure 11) shows the formulas to calculate weight, moisture content, temperature, and relative humidity from the voltage readings. Each bale also has a relay connected to a comparison function. If the calculated moisture content is below $0.5(50 \%)$, the relay outputs a value corresponding to the bale number. This number (e.g. MC1) is transferred to the next loop using a local variable.

The third loop (Figure 12) has a formula node and a case selector that is used for relay output selection. The formula node (Figure 13) inputs, x1, x2, and x3, correspond to the MC value of each strain gauge. $Y$ is the output, which goes to the case selector, and $\mathrm{z}$ indicates the order. If $\mathrm{z}$ is less than $\mathrm{x}$, then $\mathrm{y}$ becomes the value of $x$; if not, it must continue to read through the loop, and $z=z+1$. Once $z=4, z$ becomes 0 and the loop starts over. The case selector has 4 cases; case 0 indicates that everything is off. When y equal to 1 , relay number 1 is on, the pump is on, and relay number 2 and 3 are off. The relays output a True value if on (5V digital) and False if off (0V digital). The relay output signals from the case selector merge 
and go to another DAQ Assistant with digital outputs.

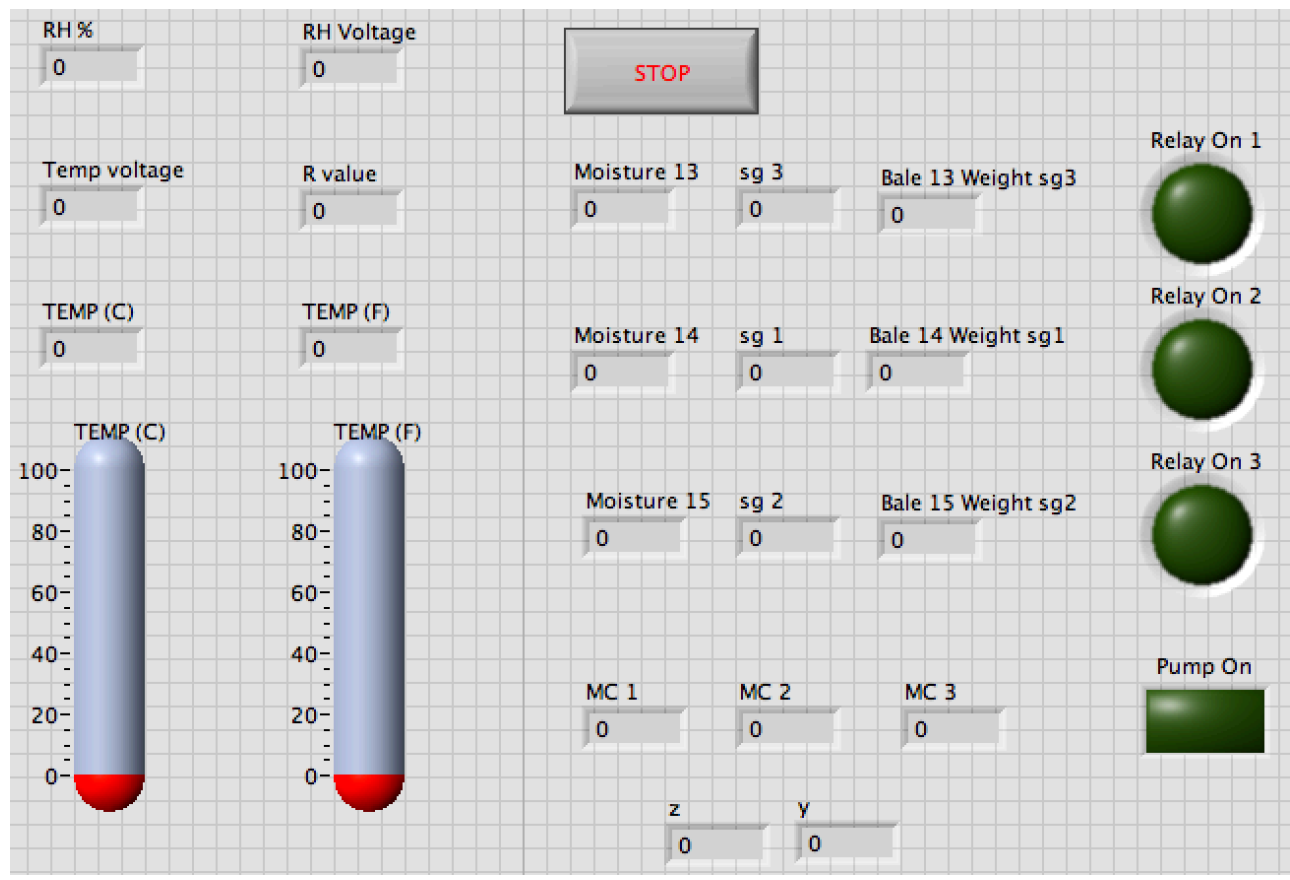

Figure 9. LabView front panel

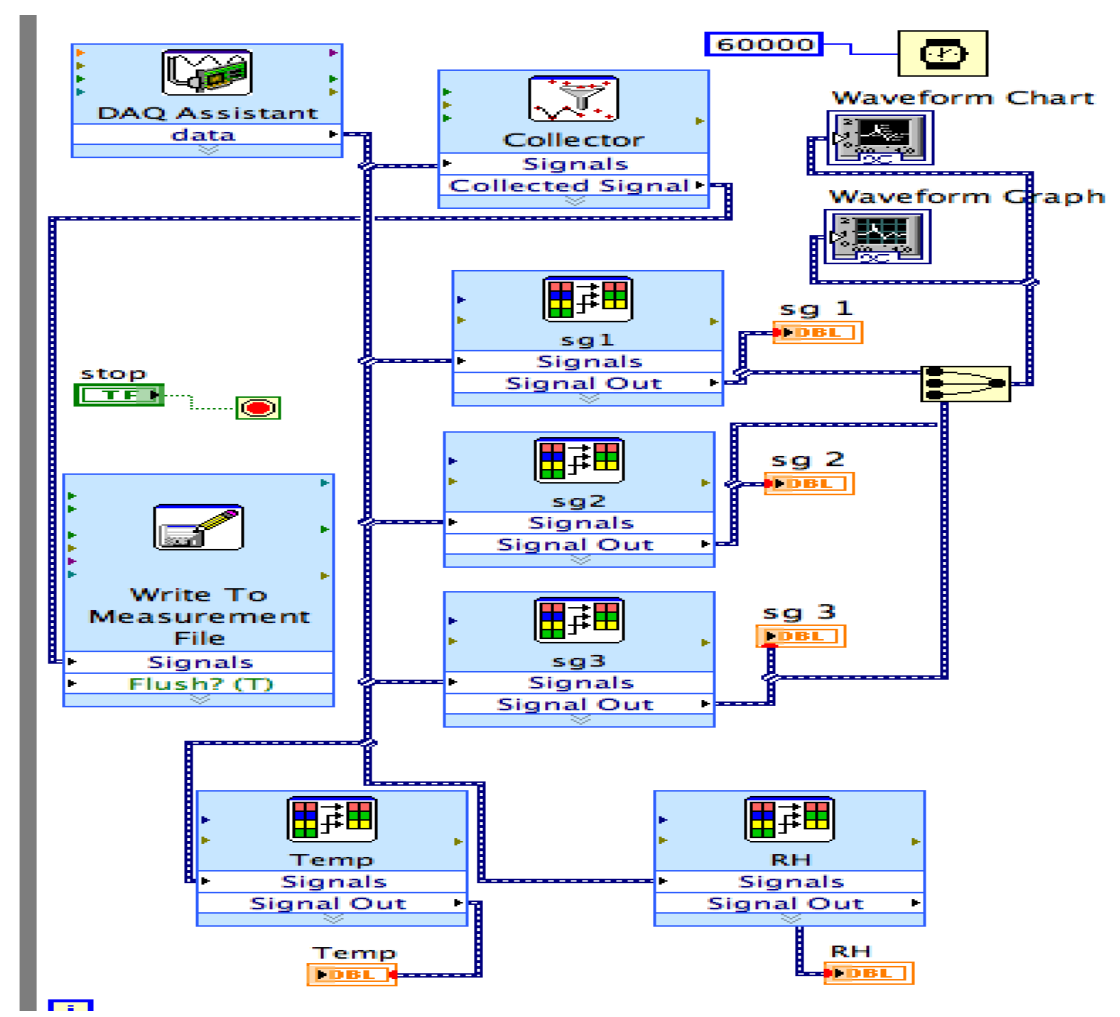

Figure 10. Data acquisition while loop 


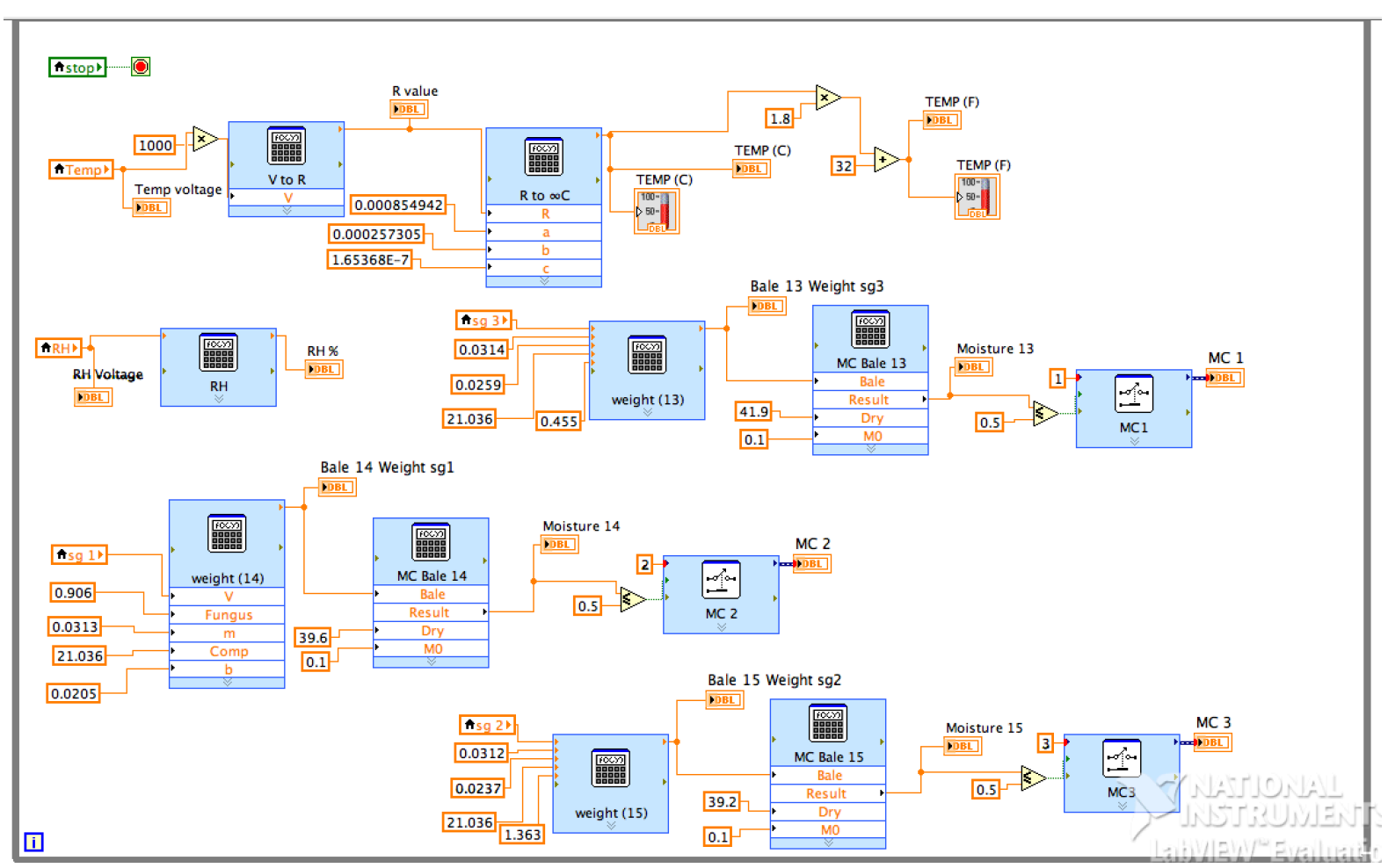

Figure 11. Calculation while loop

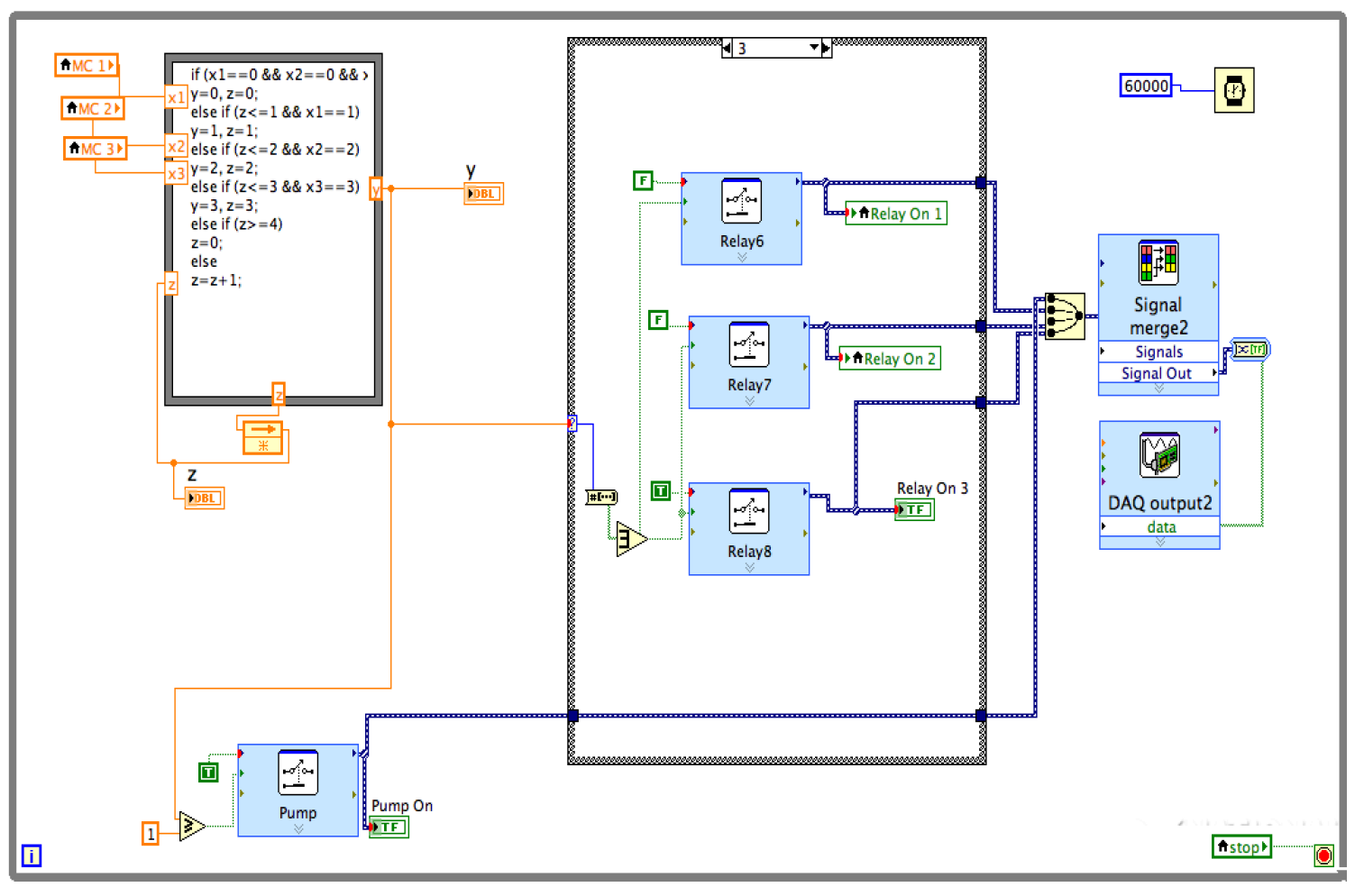

Figure 12. Relays while loop 


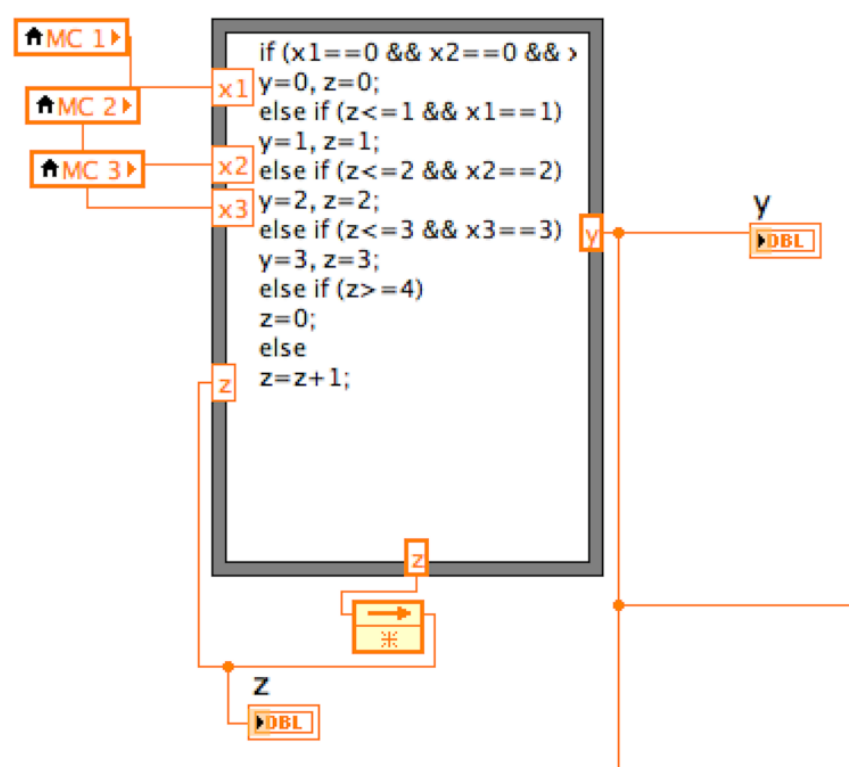

Figure 13. Formula node for relay selection

\section{System monitoring}

This system has been set up for almost three weeks, and fungal growth has been observed on the outside of the bales. This indicates that the moisture is staying within the acceptable range. The strain gauges are reading the weights and the temperature and relative humidity have remained steady. Figure 14 shows one graph generated from the strain gauge data. However, there were some issues related to instability of data logger reading. The reading was stable at the pins of the amplifier when using digital multimeter. This issue possibly can be resolve by adding low pass or high pass filter depends on the nature of the signal. The next major issue that the hose set-up for the water system. The hose was configured so that water runs out of the ends of four tubes in each of the four places in the bales. Unfortunately, this was extremely ineffective because the water never actually gets to the ends at the necessary low flow rate, running directly through the bale in the middle. In order to solve this problem, drip hose with low flow rate ( 0.5 gallons/hour) should be used. It would take much longer for each bale to recover moisture, this system should allow the water to saturate better, decreasing the amount of wastewater developed.

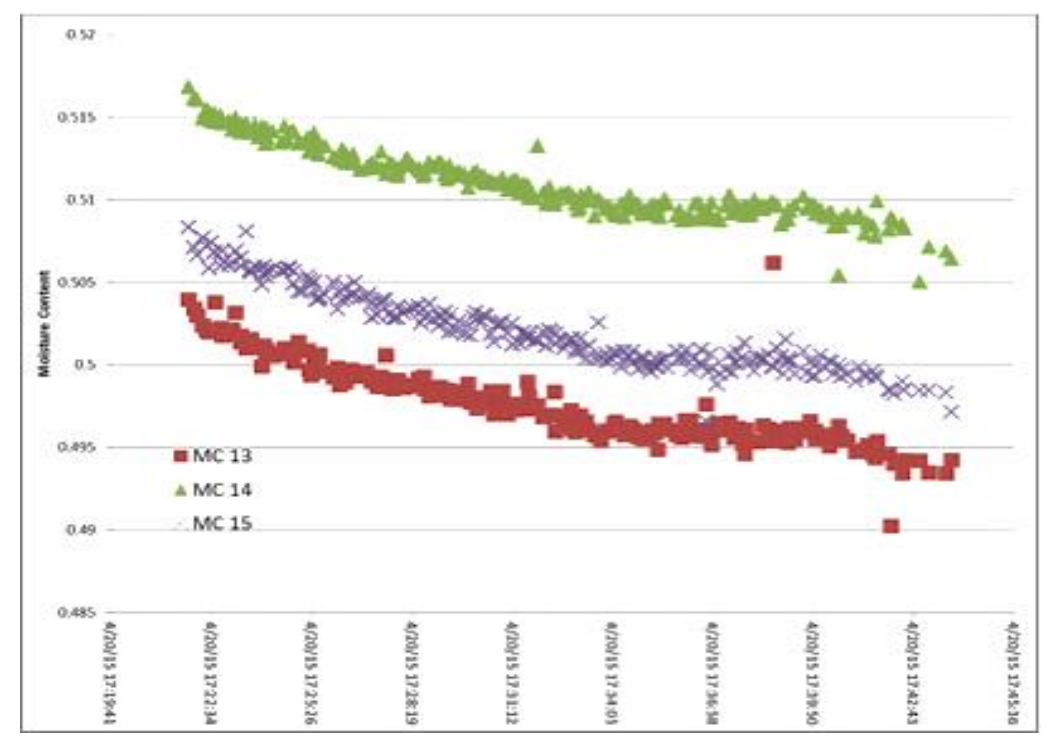

Figure 14. Example moisture content graph 


\section{CONCLUSION}

The switchgrass bale automatic weighing and watering system has developed using NI USB6225 data logger for data acquisition and LabView software. The load cell was used for weighing system. It had been able to maintain the bale moisture within the acceptable range and the fungus were observed growing. Some issues related to voltage readings and uniformity of water distribution must be addressed for future work.

\section{REFERENCES}

Inman, D., Nagle, N., Jacobson, J., Searcy, E., \& Ray, A. E. (2010). Feedstock handling and processing effects on biochemical conversion to biofuels. Biofuels, Bioproducts and Biorefining, 4(5), 562-573. https://doi.org/10.1002/bbb.241

Koff, J. P. de, \& Tyler, D. D. (2012). Improving Switchgrass Yields for Bioenergy Production. Cooperative Extension Faculty Research, (Paper 40), 1-6.

Rasnake, M., Collins, M., \& Smith, R. (2013). Switchgrass for bioenergy. University of Kentucky Cooperative Extension Service.

Scagline-Mellor, S., Griggs, T., Skousen, J., Wolfrum, E., \& Holásková, I. (2018). Switchgrass and Giant Miscanthus Biomass and Theoretical Ethanol Production from Reclaimed Mine Lands. Bioenergy Research, 11(3), 562-573. https://doi.org/10.1007/s12155-018-9915-2 